\section{Orbital vascular anatomy}

SS Hayreh

\section{Ophthalmic artery}

The pioneer worker in the study of the ophthalmic artery, particularly its branches and their variations, was Meyer ${ }^{1}$ in 1887; his observations on 20 cases were accepted more or less as classical, and most accounts of the ophthalmic artery in the text books have been essentially based on his study of those 20 specimens, ever since. Apart from occasional reports of various abnormalities, there had not been any systematic study on the ophthalmic artery till my detailed anatomical systematic studies in human beings. ${ }^{2-4} \mathrm{I}$ investigated its origin (in 170 specimens $^{2}$ ), intracranial and intracanalicular course (in 106 specimens $^{2}$ ), intraorbital course (in 61 specimens $^{3}$ ), and its branches (in 59 specimens $^{4}$ ). My studies revealed several discrepancies in Meyer's ${ }^{1}$ description, particularly about branches, presumably because of small number (20) of specimens in his study. A Medline search reveals that, since my studies, there has not been any further detailed systematic study on a large number of specimens, so that the following description is essentially based on my findings.

\section{Origin}

\section{Introduction}

Extensive accounts of the blood vessels of the orbit have been given in various text books of ophthalmology and anatomy for more than a century. Most of those accounts have been somewhat stereotyped and deal almost exclusively with the so-called 'normal pattern'; however, the orbital vascular pattern is actually very complex, with tremendous interindividual variations.

\section{Orbital arteries}

The orbit in the human being is mainly supplied by the ophthalmic artery, with minor contributions from the external carotid artery.
The ophthalmic artery is the first major branch of the internal carotid artery. It arises soon after the latter has emerged from the cavernous sinus by penetrating the dura (Figures 1, 2, 3a, and 4); however, in two specimens it arose just while the internal carotid was piercing the dura, and, in about $7 \%$, the origin was less than $1 \mathrm{~mm}$ above the site of penetration. ${ }^{2}$ The ophthalmic artery arises from the internal carotid, usually at its anteromedial or superomedial aspects (Figures 1 and 2). In about $8 \%$ of the specimens in my study, it was arising while the internal carotid artery lay in the cavernous sinus (Figures $3 b$ and 5). In two of my 170 specimens, the ophthalmic artery did not arise from the internal carotid artery but was a branch of the middle meningeal artery and entered the orbit 
through the superior orbital fissure (Figures $6 \mathrm{f}$ and $\mathrm{g}$ ). In another four specimens, the ophthalmic artery had two trunks - a small one arising as usual from the internal carotid artery, and a large trunk from the middle meningeal artery (Figures 6b-e).

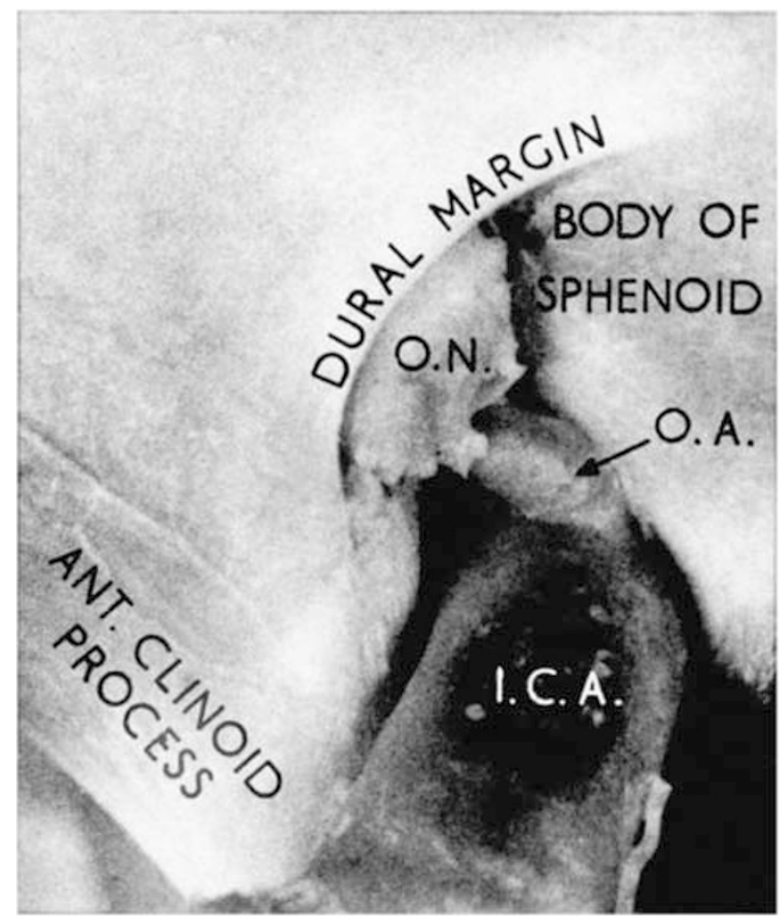

Figure 1 Origin and intracranial part of right ophthalmic artery, with optic canal intact (reproduced from Hayreh and Dass $^{2}$ ).

\section{Abnormal origins of ophthalmic artery}

According to Krause's $s^{5}$ Law, 'The varieties originate through abnormal development of normal anastomoses.' Figure 7 shows the various anastomoses between the ophthalmic artery and various branches of the external carotid artery. In addition, it may have fine anastomoses with intracavernous part of the internal carotid artery via the superior orbital fissure (see later Figure 16). When the ophthalmic artery does not arise normally from the internal carotid artery (as was the case in two of my specimens), or after normal development later becomes obliterated, or the trunk arising from the internal carotid artery is small, then one of the anastomoses with the adjoining arteries has the potential to become the main source of blood supply. That can also happen if the internal carotid artery is absent ${ }^{6-19}$ or hypoplastic. ${ }^{20-23}$ The following abnormal modes of origins of the ophthalmic artery have been reported in the literature.

(a) From the middle meningeal artery: This is the most common abnormal origin of ophthalmic artery reported in the literature. ${ }^{1,24-43}$ This mode of origin was seen in six specimens (four persons) in my study ${ }^{2}$ (Figures 6b-e). It is by enlargement of anastomoses between the recurrent branch of the lacrimal artery and the orbital branch of the middle meningeal artery through the superior orbital fissure or a foramen in the greater wing of the sphenoid. This anastomosis is present during foetal life (see below). It becomes stronger when the ophthalmic artery or its parent trunk is poorly developed or completely obliterated. The trunk that arises from the middle meningeal artery has also been called an 'accessory
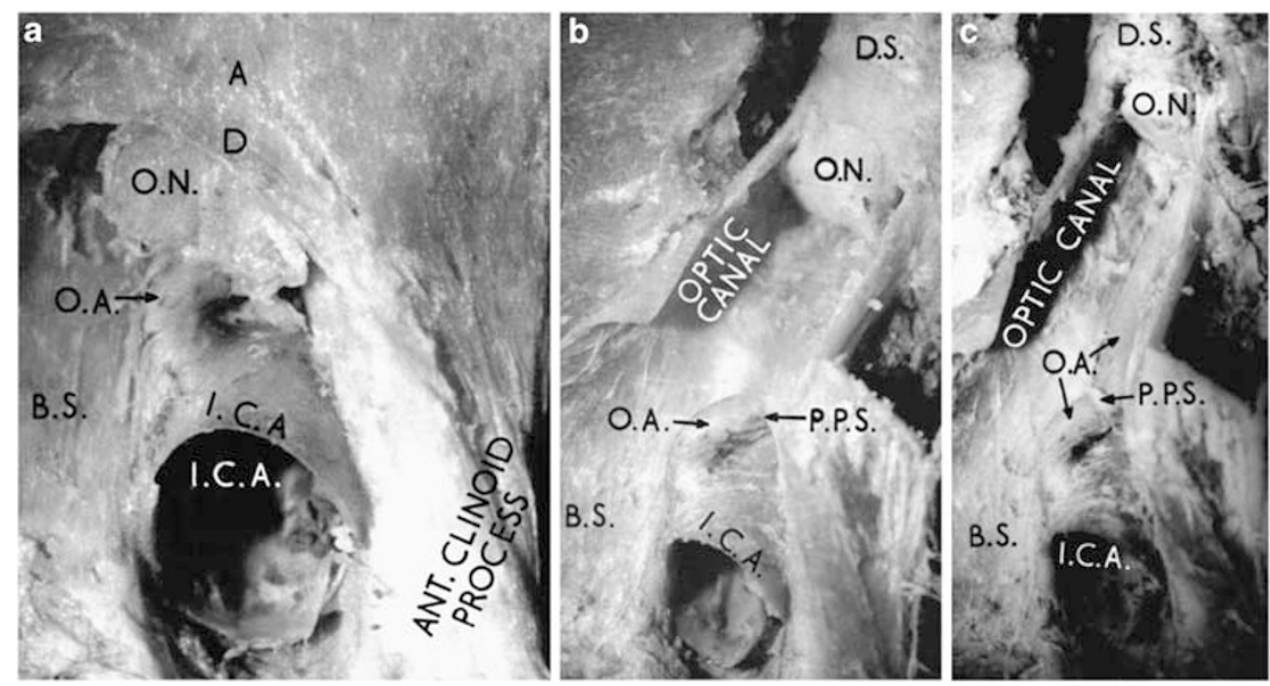

Figure 2 All from one specimen: (a) origin and intracranial part of right ophthalmic artery, with optic canal intact; (b) on opening the optic canal, in addition to the above, site of penetration of the ophthalmic artery into the dural sheath is seen; and (c) origin and intracranial and intracanalicular course of the ophthalmic artery, as seen on opening the optic canal and removing the covering dural sheath (reproduced from Hayreh and Dass ${ }^{2}$ ). 
a
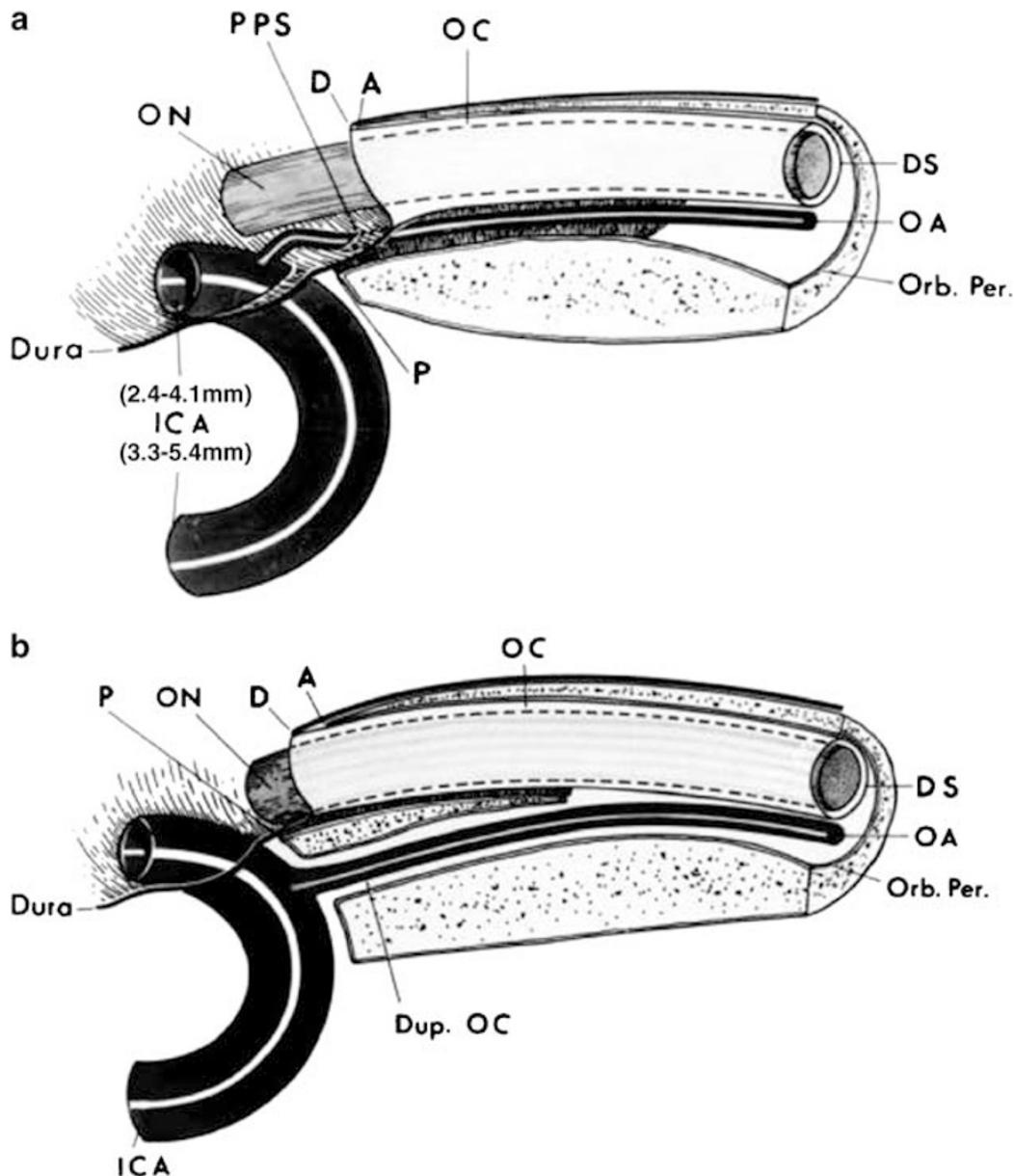

Figure 3 Lateral views of the optic canal, cavernous, and intracranial part of the internal carotid artery, and origin of the ophthalmic artery (reproduced from Hayreh ${ }^{67}$ ) (a) Details of the usual origin and intracranial and intracanalicular course of the ophthalmic artery. The diameters of the lumen of the internal carotid artery before and after the origin of the ophthalmic artery are shown. (b) An extradural origin of the ophthalmic artery and its course through duplicate optic canal.

ophthalmic artery'. ${ }^{41}$ Occasionally the lacrimal artery, instead of arising from the ophthalmic artery, may arise from the middle meningeal artery. ${ }^{1,4,25,28,31,34,35,38,44-52}$ Rarely, the middle meningeal artery may arise from the ophthalmic artery instead of from the maxillary artery. ${ }^{31,33,35,42,53-58}$

An abnormal origin of the ophthalmic artery from the external carotid artery may also be explained by the comparative anatomy of the orbital arteries. ${ }^{36,50,59,60}$ In the lower animals, the ophthalmic artery is derived from the external carotid artery, but as we go up the evolutionary ladder of the animal kingdom, the ophthalmic artery tends to arise from the internal carotid instead of the external carotid. For example, although rhesus monkeys have a normal ophthalmic artery, a large lacrimal artery connects both the ophthalmic artery and the middle meningeal artery, so that the middle meningeal artery contributes a significant blood supply to the orbit, in addition to the ophthalmic artery. ${ }^{61}$ In the intermediate species, internal and external ophthalmic arteries arise from the internal and external carotid arteries, respectively, the former supplying the eyeball and the latter the orbit, and the anastomotic connection between the two can maintain the circulation from either source.

(b) From the intracavernous part of the internal carotid artery: In such a case, it passes through the superior orbital fissure or duplicate optic canal (Figures $3 \mathrm{~b}$ and 5). ${ }^{1,2,62-64}$ This was seen in eight of my cases. ${ }^{2}$

(c) From the middle cerebral artery: This rare occurrence has been reported when the ipsilateral internal carotid artery is missing. ${ }^{12,14}$

(d) From anterior cerebral artery: This was seen on angiography in one case. ${ }^{65}$

(e) From the posterior communicating artery: There is one report of such an origin. ${ }^{13}$

(f) From basilar artery: This was reported on angiography in one case. ${ }^{66}$ 


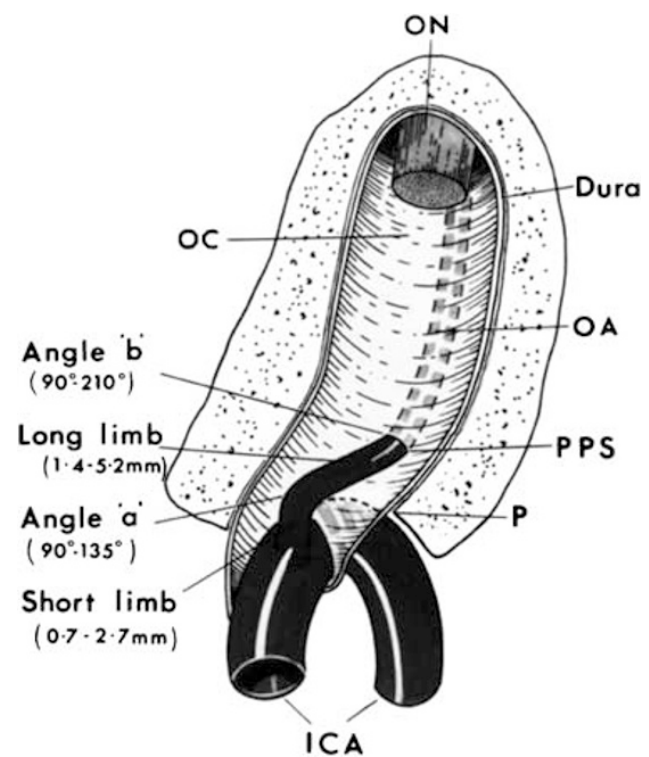

Figure 4 Origin and intracranial and intracanalicular course of the ophthalmic artery and its subdivisions, as seen on opening the optic canal (reproduced from Hayreh ${ }^{67}$ ).
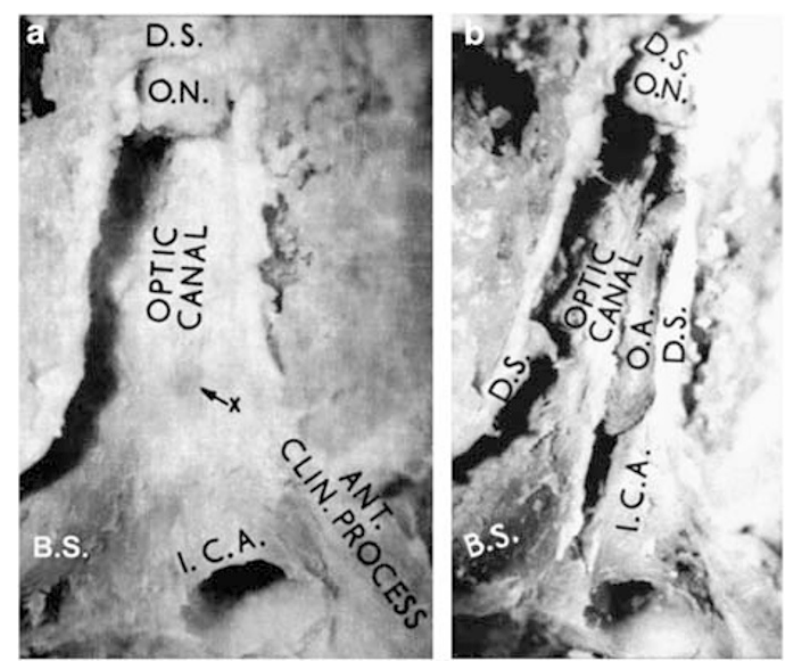

Figure 5 Both from one specimen. (a) The extradural origin of the right ophthalmic artery, so that no ophthalmic artery is seen even on opening the optic canal; a thinning of the dural sheath is seen at ' $\mathrm{X}$ ', indicating the position of the artery. (b) The ophthalmic artery is seen after removing the dural sheath covering it (reproduced from Hayreh and Dass ${ }^{2}$ ).
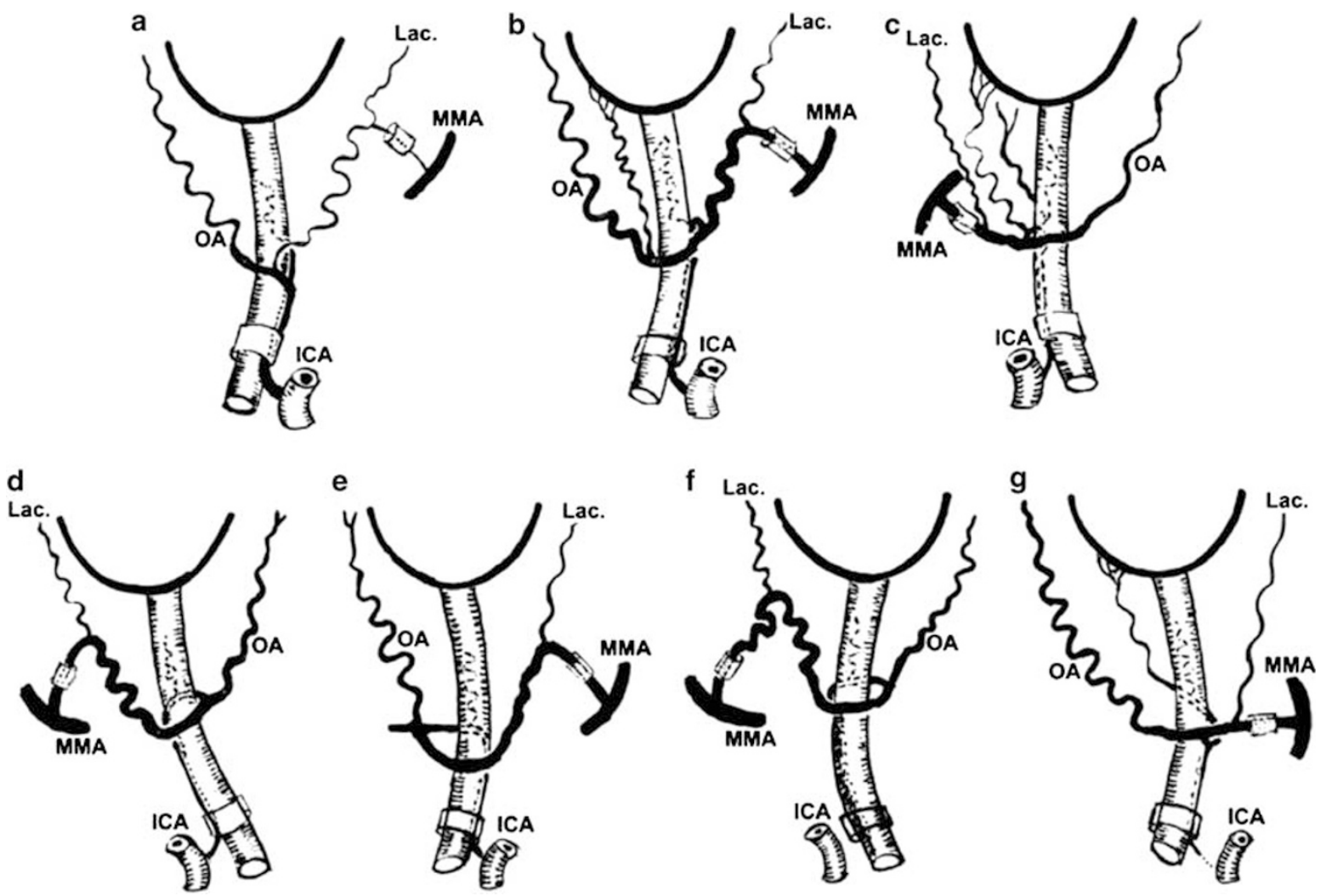

Figure 6 A diagrammatic representation of variations in origin and intraorbital course of ophthalmic artery. (a) Normal pattern. (b-e) The ophthalmic artery arises from the internal carotid artery as usual, but the major contribution comes from the middle meningeal artery. ( $\mathrm{f}$ and g) The only source of blood supply to the ophthalmic artery is the middle meningeal artery, as the connection with the internal carotid artery is either absent (f) or obliterated $(\mathrm{g})$ (reproduced from Hayreh and Dass ${ }^{3}$ ). 


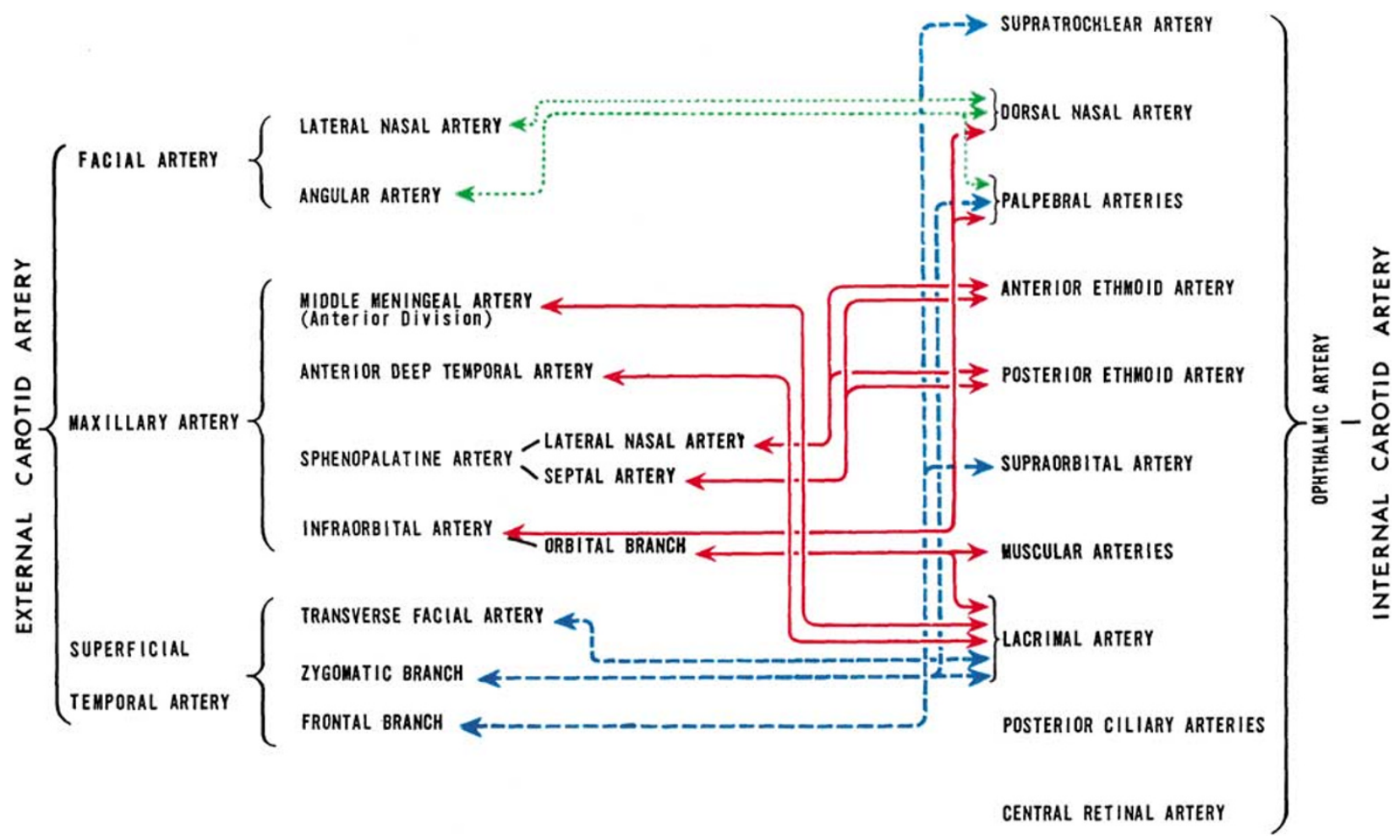

Figure 7 A diagrammatic representation of anastomoses of the ophthalmic artery with various branches of the external carotid artery (reproduced from Hayreh ${ }^{67}$ ).

\section{Course}

This is described in detail elsewhere. ${ }^{2,3}$ The entire course of the ophthalmic artery can be divided into three parts: (a) intracranial, ${ }^{2}$ (b) intracanalicular, ${ }^{2}$ and (c) intraorbital. ${ }^{3}$

\section{Intracranial course}

During this part, the ophthalmic artery is intimately related to the proximal part of the internal carotid artery (Figures 1 and 2), to which it frequently adheres for some distance. $^{2}$ It lies in the subdural space and is attached to the undersurface of the optic nerve by a loose meshwork of fibrovascular connective tissue. The initial part of the ophthalmic artery (which may be entirely or partly intracranial) follows a characteristic course, which I divided into four parts - from the origin onwards these are: short limb, angle ' $a$ ', long limb, and angle ' $b$ '

(Figure 4). These are discussed at length elsewhere. ${ }^{2}$ In the region of the optic canal, the two layers of the dura mater are fused but they split up in the cranial cavity to form the cavernous sinus, while in the orbit the inner layer forms the dural sheath of the optic nerve and the outer layer forms the orbital periosteum. In the cranial cavity, the ophthalmic artery mostly lies in the subdural space, but in the orbit it lies always between the two layers; therefore, it has to pierce the inner dural layer while passing from the cranial cavity to the orbit. The site where it pierces the inner dural layer is usually in the optic canal (Figures 2b, 3a, and 4). In my study, in $85 \%$ the entire intracranial course lay in the subdural space, in $10 \%$ partly subdural and partly within the dural sheath, and in 5\% it was extradural (Figures $3 b$ and 5). The intracranial course may be absent in some cases.

Sometimes the origin or the initial parts of the ophthalmic artery, or both, are closely related to the sphenoid bone (Figure 1). Therefore, the likelihood of involvement of the ophthalmic artery and optic nerve in sphenoidal sinus disease must be kept in mind.

\section{Intracanalicular course}

This section lies in the optic canal, usually inferolateral to the optic nerve (Figures 2b, c, 4, 5b, and 8). It usually lies partly in the subdural space and partly within the substance of the dural sheath, less often entirely within the dural sheath with no subdural course (Figures 2b, c, and 5). During its course in the dural sheath, the artery is separated from the surrounding dura by areolar tissue (Figures 2c and 5b), except where it proximally pierces the dural sheath (Figure $2 b$ and $c$ ). In my study, ${ }^{2}$ out of 


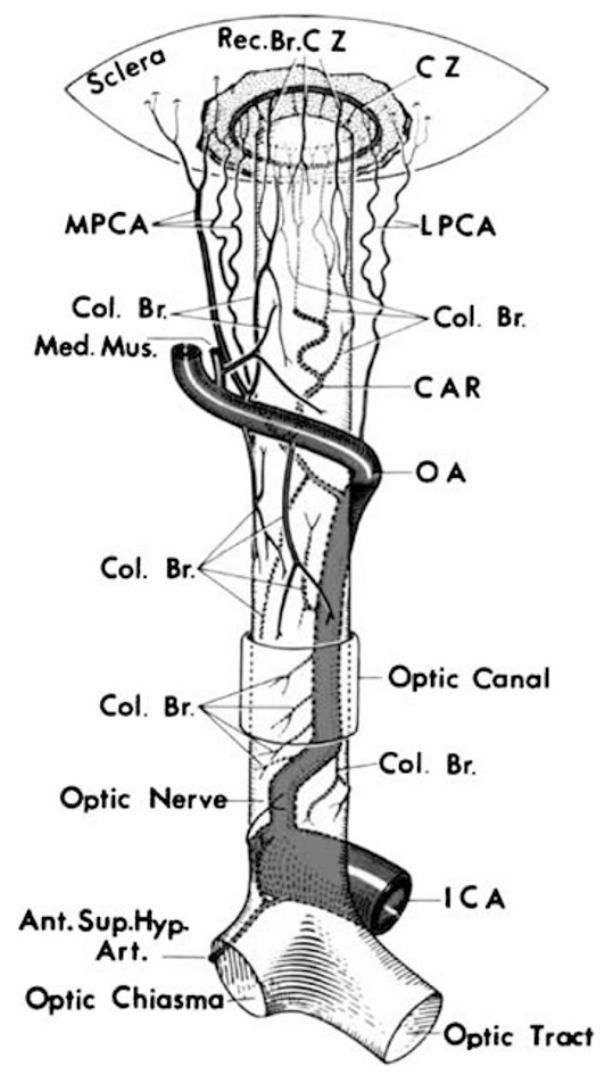

Figure 8 A diagrammatic representation of the origin, course, and branches of the ophthalmic artery (reproduced from Hayreh SS. Br J Ophthalmol 1963; 47: 651-663).

about $8 \%$ of specimens with an opthalmic artery of extradural origin, about $3 \%$ of the arteries entered the orbit from the cranial cavity in a separate bony canal (duplicate optic canal) enclosed in a dural covering (Figure 3b). This canal is separated from the optic canal by a thin bony lamina, and the dural covering of the artery joins the dural sheath of optic nerve on its inferolateral aspect near the orbital end of the canal. In one specimen, the artery entered the orbit through the most medial part of the superior orbital fissure medial to the oculomotor nerve. In the optic canal, the optic nerve is attached to the surrounding dura by fibrous bands (Figure 9); through these bands run the fine branches from this part of the ophthalmic artery. In the event of fracture of the canal, if these fibrous bands are torn, the vessels they contain are also torn, resulting in optic nerve ischaemic damage.

\section{Intraorbital course}

The ophthalmic artery enters the orbit at its apex through the optic canal or rarely through the duplicate optic canal (Figure $3 b$ ) or superior orbital fissure. ${ }^{3}$ The intraorbital course can be divided into three parts (Figures 8, 10, and

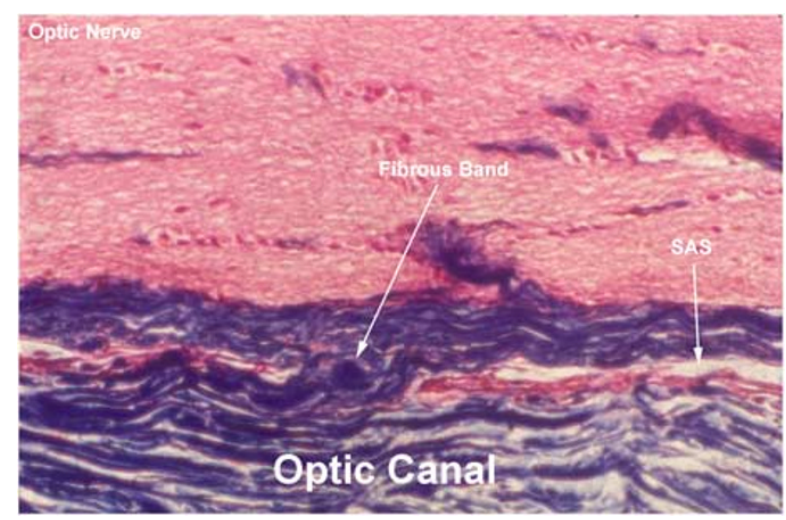

Figure 9 Longitudinal histological section of the optic nerve in the region of optic canal, showing fibrous band connecting the optic nerve with the surrounding sheath and capillary subarachnoid space.

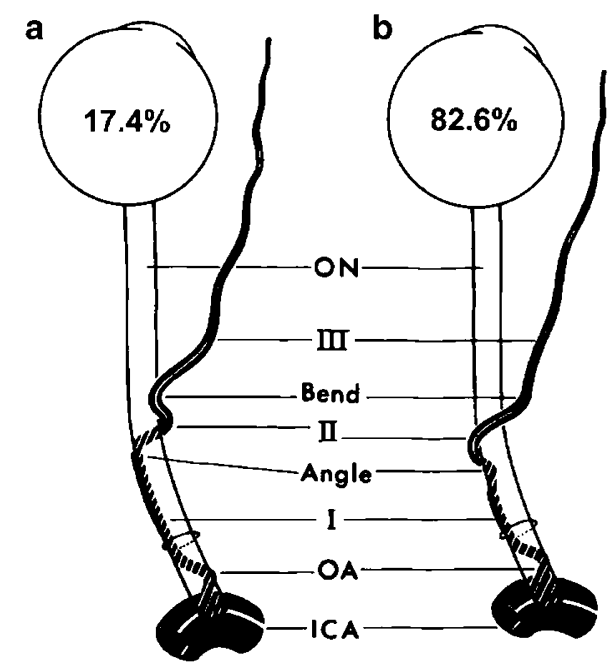

Figure 10 Course of the ophthalmic artery when it crosses (a) under and (b) over the optic nerve and their incidence (reproduced from Hayreh ${ }^{67}$ ).

11). The ophthalmic artery changes direction at two places: (i) at the junction of the first and second part, and (ii) between the second and third part.

The first part

This extends from the point where it enters the orbit to the point where it bends to become the second part (Figures 8, 10, and 11). This part of the artery usually lies in very close relationship to the inferolateral aspect of the optic nerve, attached to the nerve only by fat and loose connective tissue, and rarely firmly adherent to the optic nerve. When the only or major source of blood supply is from the middle meningeal artery, this part is of small calibre (Figure 6b-g). 


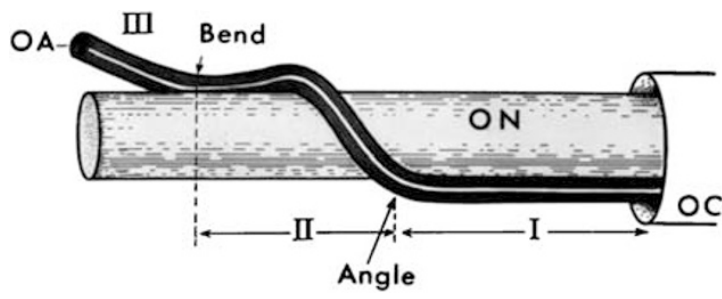

Figure 11 Intraorbital course of the ophthalmic artery, as seen from the lateral side of the optic nerve (reproduced from Hayreh $^{67}$ ).

\section{The second part}

This part crosses over (in 83\%) (Figures 8, 10a, 11, and 12a) or under (17\%) (Figure 10b) the optic nerve to go medial to the optic nerve. In my study, when this pattern of crossing over or under the optic nerve was evaluated in the two orbits of the same person, in $70 \%$ it crossed over the optic nerve on both sides, in 5\% under the optic nerve on both sides, and in the rest the crossing pattern was different in the two orbits. The second part of the artery lies in close contact with the optic nerve but is only loosely attached to the dural sheath of the optic nerve.

\section{The third part}

This runs forward medial to the optic nerve and, unlike the first two parts, is not intimately related to the optic nerve (Figures 10-12). It runs forward above the medial rectus and under the superior oblique, to reach the medial wall of the orbit close to the anterior ethmoid foramen. This segment of the artery is usually the only one that shows marked tortuosity in the majority. It is usually anchored to the medial wall of the orbit by the short, stout trunk of the anterior ethmoid artery. After that, it runs forward close against the medial orbital wall, passing below the trochlea, and then generally runs upwards and forward to lie nearly midway between the medial palpebral ligament and the orbital margin. A tortuous loop is sometimes present just proximal to the termination of the artery.

\section{Termination of the ophthalmic artery}

It normally terminates at the superomedial angle of the orbital opening into supratrochlear and dorsal nasal branches (Figure 12). ${ }^{3,4}$ However, in $26 \%$ of my specimens, the main part of the ophthalmic artery terminated at the level of the anterior ethmoid foramen by bifurcating into two trunks, one anterior ethmoid artery and the other a continuation of the ophthalmic artery to the superomedial angle of the orbital opening. ${ }^{3}$

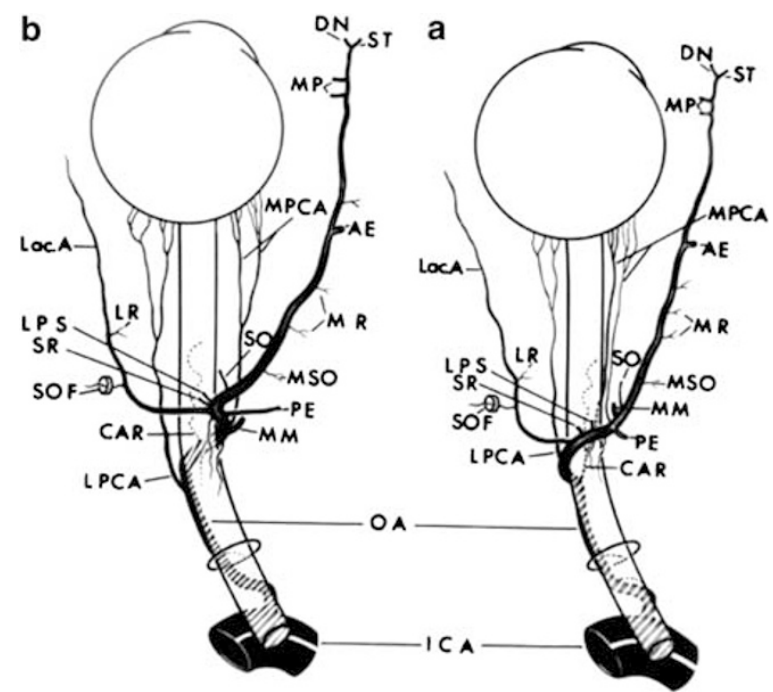

Figure 12 The pattern of the branches of the ophthalmic artery when it crosses (a) over and (b) under the optic nerve (reproduced from Hayreh ${ }^{67}$ ).

\section{Branches of the ophthalmic artery}

I have described in detail the order and site of origin of the various branches of the ophthalmic artery and their supply. ${ }^{3}$ In my study of 59 human orbits, the most impressive finding was these wide variations in the order and site of origin of these branches, where no two ophthalmic arteries had identical branching patterns, not even on the two sides of the same individual. Certain broad generalizations, however, can be made. Whether the ophthalmic artery crosses over or under the optic nerve in the second part of its course made an evident difference in the mode of origin of its branches, as shown in Table 1 and Figure 12. However, importantly, all kinds of variations were seen in the pattern described in Table 1 . The variations are so marked that it is wrong to look for the so-called 'normal' pattern. It is only possible to speak of a 'usual' pattern, which is more common than any of the others. It is beyond the scope of this paper to discuss each and every branch of the ophthalmic artery even briefly - I have given a detailed account of the origin, supply, and other aspects of each one of those elsewhere. ${ }^{4}$ When the ophthalmic artery has two trunks (see above), the ocular branches still maintain their connection with the ophthalmic artery arising from the internal carotid artery.

\section{Genesis of variations of origin and course of the ophthalmic artery and pattern of its branches}

I have discussed the pathogenesis of variations in the origin and course of the ophthalmic artery and in the 
Table 1 arder of origin of branches of ophthalmic artery as seen in my series ${ }^{4}$

\begin{tabular}{cll}
\hline Order of origin & Ophthalmic artery crosses over optic nerve & Ophthalmic artery crossed under optic nerve \\
\hline 1 & Central retinal + medial posterior ciliary & Lateral posterior ciliary \\
2 & Lateral posterior ciliary & Central retinal \\
3 & Lacrimal & Medial muscular \\
4 & Muscular to superior rectus and/or levator & Medial posterior ciliary \\
5 & Posterior ethmoid and supraorbital, jointly or & Lacrimal \\
& separately & \\
6 & Medial posterior ciliary & Muscular to superior rectus and levator \\
7 & Medial muscular & Posterior ethmoid and supraorbital jointly or \\
& & separately \\
8 & Muscular to superior oblique and medial rectus, & Muscular to superior oblique and medial rectus, \\
& jointly or separately or to either & jointly or separately or to either \\
9 & To areolar tissue & Anterior ethmoid \\
10 & Anterior ethmoid & To areolar tissue \\
11 & Medial palpebral or inferior medial palpebral & Medial palpebral or inferior medial palpebral \\
12 & Superior medial palpebral & Superior medial palpebral \\
Terminal & i. Dorsal nasal & i. Dorsal nasal \\
& ii. Supratrochlear & ii. Supratrochlear \\
\hline
\end{tabular}

${ }^{a}$ This table is reproduced from Hayreh. ${ }^{4}$

pattern of its branches at length elsewhere. ${ }^{67}$ The following is a brief summary. The genesis can best be explained on the basis of the developmental history of the orbital arterial bed, as shown by the findings of Padget. ${ }^{68}$

During the formation of the definitive arterial stem from the early diffuse capillary plexus, there is a gradual disappearance of certain vessels and appearance of others. The development of the definite ophthalmic artery is very complicated and relatively late. All the stages are still not known. At $4-6 \mathrm{~mm}$ stage, most of the primitive eye is supplied by the 'primitive dorsal ophthalmic artery', a branch of the internal carotid artery at its bifurcation. At $5.5 \mathrm{~mm}$ another branch of the internal carotid artery, called the 'primitive ventral ophthalmic artery', arises from the cranial division of the internal carotid artery. At $12-14 \mathrm{~mm}$, as the eye shifts away from the brain, the two primitive ophthalmic arteries are drawn out in length. Meanwhile, the primitive dorsal opthalmic artery gives out the hyaloid artery, and the part of the original artery distal to the hyaloid artery forms the lateral posterior ciliary artery. At $16-18 \mathrm{~mm}$, the permanent stem of the ophthalmic artery appears and annexes the ocular branches of the primitive dorsal ophthalmic artery. Thus, the permanent ophthalmic artery represents the primitive dorsal ophthalmic artery. The original primitive dorsal ophthalmic artery lay well cranial to the optic stalk, but the adult position is caudal to the optic stalk. This caudal migration takes place by a series of anastomotic loops (anastomotic progression) from the carotid during the postbranchial stage when the expanding brain and cerebral arteries become more and more withdrawn from the developing optic nerve and the eyeball. At 21-24 mm, the stem of the ophthalmic artery annexes the distal end of the attenuated primitive ventral ophthalmic artery and that forms the medial posterior ciliary artery. This anastomosis takes place ventral to the optic nerve and is usually linked with the hyaloid branch (central retinal artery) of the ophthalmic stem. It is followed by the interruption of the primitive ventral ophthalmic artery just proximal to the secondary anastomosis, so that the medial posterior ciliary artery arises in common with the central retinal artery. By $20 \mathrm{~mm}$, all the ocular branches of the ophthalmic artery are established.

No orbital branch of the ophthalmic artery appears until the $16-18 \mathrm{~mm}$ stage is reached. Orbital branches are of a totally different origin from that of the ocular branches. The second pharyngeal artery gives out the stapedial artery, and at $16-18 \mathrm{~mm}$, the latter has two primary divisions: one of them is called the supraorbital branch. The supraorbital branch enters the orbit at the $18 \mathrm{~mm}$ stage. At $20 \mathrm{~mm}$, the ophthalmic artery stem establishes anastomoses with the supraorbital division of the stapedial artery. Later on, the stapedial artery loses its connection with the second arch artery and through its maxillomandibular division is annexed to the maxillary branch of the external carotid. The maxillomandibular and the supraorbital divisions of the stapedial artery form the ultimate middle meningeal artery.

All the orbital branches of the adult ophthalmic artery are derived from the supraorbital division of the stapedial artery. At $24 \mathrm{~mm}$, three branches arise from the supraorbital division: frontal, supraorbital, and anterior ethmoid, near the superomedial aspect of the optic nerve. The stem of the lacrimal artery develops some time 
between the 24 and $40 \mathrm{~mm}$ stage. Toward the end of this period, the original supraorbital division dwindles at the orbital margin, that is, between its proximal and distal parts, which now belong to the middle meningeal and the ophthalmic arteries, respectively, thus forming the adult pattern of the ophthalmic artery. This embryonic connection may persist in adult life and is responsible for the abnormal origin of the ophthalmic artery from the middle meningeal artery discussed above.

At $24 \mathrm{~mm}$ stage, the optic nerve, at the origin of the three primary ocular branches of the ophthalmic artery (ie central retinal artery and medial and lateral posterior ciliary arteries), is surrounded by an arterial ring, the components of which represent several secondary
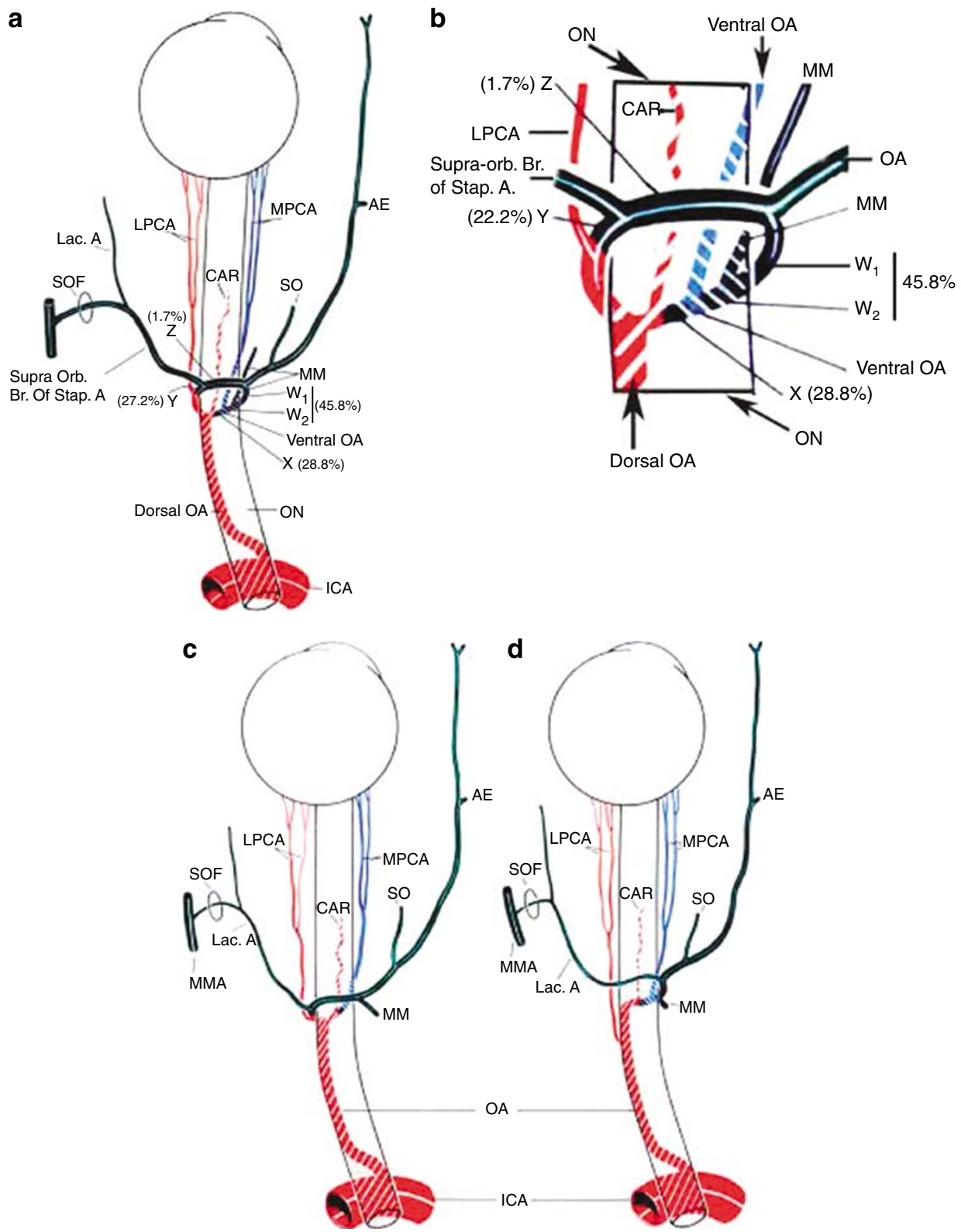

Figure 13 Schematic representation of the developmental origin of the various parts of the ophthalmic artery, and genesis of variations of origin and course of the ophthalmic artery and pattern of its branches. (a) This shows (i) the various original developmental components, (ii) secondary anastomoses connecting the various developmental components and resulting in the formation of an embryonic ring around the optic nerve during embryonic life, and (iii) four segments (W, X, Y, and Z) of the embryonic ring. (b) A magnified view of the embryonic ring and its various segments. (c and d) These show the adult patterns and their various embryonic origins when the ophthalmic artery crosses over (c) and under (d) the optic nerve (a, c, and d reproduced from Hayreh ${ }^{67}$ ). Colour scheme showing derivatives of: red=primitive dorsal ophthalmic artery; blue=primitive ventral ophthalmic artery; green $=$ stapedial artery; and black = secondary anastomoses. 
anastomoses. The less well-developed ventral portion represents in part the anastomosis between the primitive ventral ophthalmic artery and the ophthalmic stem. The dorsal part of the ring is larger and probably of more recent origin, and is responsible for the future definitive ophthalmic artery passing from the ventral to the dorsal aspect of the optic nerve, as is typically seen in the adult. By $39 \mathrm{~mm}$, a small part of the ventral portion of this arterial ring is usually destined to disappear, whereas all the other parts are retained, leading to the adult configuration of the ophthalmic artery.

Figure 13a, based on the developmental findings of Padget ${ }^{68}$ represents diagrammatically the various developmental components of this arterial ring. Judging from 59 specimens in my study, I have found that any one of the following four segments of the ring (W, X, Y, or $Z$ ) may disappear, as the adult configuration of the ophthalmic artery is formed:

Segment Developmental location

W

Between the supraorbital branch of stapedial artery and primitive ventral ophthalmic artery.

$\mathrm{X} \quad$ Between the primitive ventral and dorsal ophthalmic arteries.

$\mathrm{Y} \quad$ Between the supraorbital branch of stapedial artery and primitive dorsal ophthalmic artery. Segment of the supraorbital branch of stapedial artery between $\mathrm{W}$ and $\mathrm{Y}$.

When the ophthalmic artery crosses over the optic nerve, the segment $Y$ may be situated between the lateral posterior ciliary artery and the supraorbital branch of the stapedial artery in $84.1 \%$, whereas in $15.9 \%$ it may be between the supraorbital branch and the stem of the ophthalmic artery. Padget ${ }^{68}$ has illustrated the latter type of connection in an embryo. However, it is difficult to determine the above exact relationship when the ophthalmic artery crosses under the optic nerve.

The incidence of disappearance of the various segments in the 59 cases of my study was found to be as follows:

$\begin{array}{llllll}\text { Segment involved } & \mathrm{W} & \mathrm{X} & \mathrm{Y} & \mathrm{Z} & \mathrm{Nil}^{*} \\ \text { Incidence (\%) } & 45.8 & 28.8 & 22.2 & 1.7 & 1.7\end{array}$

*In this specimen the remnants of the embryonic ring were still present in adult life (Figure 14), although the segments $\mathrm{Y}$ and $\mathrm{Z}$ were underdeveloped, so that the ophthalmic artery crossed under the optic nerve.

These were the only segments which I saw disappear in the specimens examined in my study, but it is quite

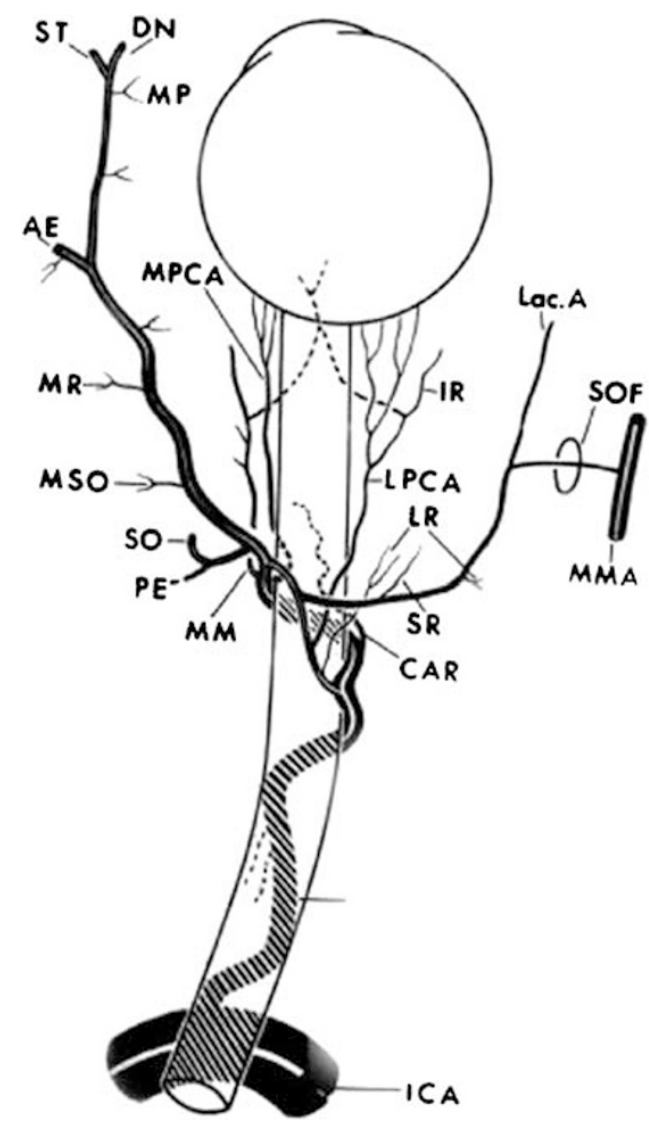

Figure 14 The course and branches of the ophthalmic artery in a case where the embryonic arterial ring persisted in adult life (reproduced from Hayreh ${ }^{67}$ ).

possible that more than one segment may disappear, as can be seen in a case reported by Chanmugam, ${ }^{36}$ in which the ocular arteries arose from the internal carotid and the orbital from the middle meningeal, with no communication between the two. Obviously such a pattern must have been owing to the disappearance of segments $\mathrm{W}$ and $\mathrm{Y}$ (Figure 13a).

The adult pattern of branching, as seen in my series, strongly suggests that the large medial muscular artery (Figure 12), which generally supplies the medial and inferior recti and inferior oblique muscles, ${ }^{4}$ arises in the embryo from segment $\mathrm{W}$ of the ring-dividing it into two parts $-W_{1}$ (between the origin of this and the distal part of the ophthalmic artery) and $\mathrm{W}_{2}$ (between the medial muscular artery and medial posterior ciliary artery) (Figure 13a). When the ophthalmic artery crosses under the optic nerve in the adult pattern (Figure 12b), the medial muscular artery is usually an independent branch arising after or at the same place as the medial posterior ciliary artery, from the second part of the ophthalmic artery; this was seen in 13 out of 15 specimens, which strongly supports the above 
hypothesis. However, the adult pattern in certain cases in my series very much suggested the possibility that the medial muscular artery may arise from the $X$ segment. Unfortunately, the work of Padget, ${ }^{68}$ although very useful, is of no help in elucidating this point, as she did not give any account of the medial muscular artery in her description or illustration.

Thus, the crossing of the ophthalmic artery over or under the optic nerve and the branching pattern depends upon which segment of the ring has disappeared. If $\mathrm{W}$ or $X$ disappears, the artery will cross over the optic nerve (Figures $13 \mathrm{~b}$ and 15), and if $\mathrm{Y}$ or $\mathrm{Z}$ disappears, the artery will cross under the optic nerve (Figures 13c and 16). In my series, examples of each type were seen. The variations in the pattern of origin of various branches depend upon which segment disappears. For example, the variations in the pattern of origin of the ocular arteries, the lacrimal artery, and the medial muscular artery are determined by which of the four segments (W, X, Y, and Z) disappears (Figures 13, 15, and 16). The adult pattern suggests that, in about one case out of five, the segment $\mathrm{W}$ joins one of the subdivisions of the medial posterior ciliary artery instead of joining its main stem, so that the disappearance of a segment of that subdivision proximal to this union results in splitting the medial posterior ciliary artery into two parts, one arising from the proximal part of the ophthalmic artery and the other one from the distal part. Because of the wide variations in the pattern of branching of the adult ophthalmic artery and the small amount of work that has been carried out so far to find all the variations of distribution of these branches of the ophthalmic artery in early embryos, particularly of the orbital branches, it may be difficult to interpret the adult pattern of branches in every case on the basis of the disappearance of these segments, although generally it is possible.

\section{External carotid artery contribution}

The external carotid artery normally contributes only to a small extent to the orbital blood supply via the infraorbital artery and orbital branch of the middle meningeal artery.

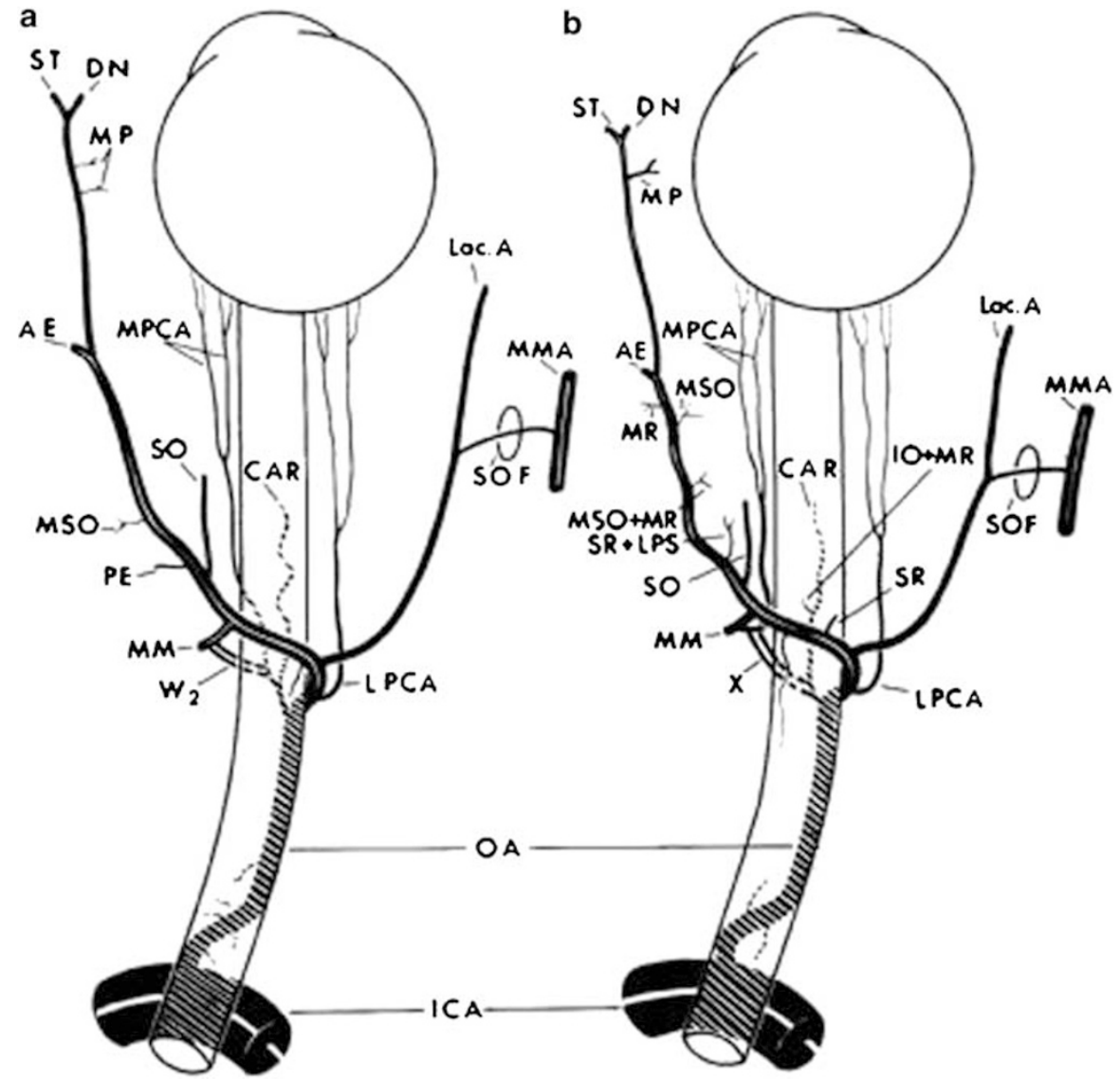

Figure 15 Origin, course, and branches of the ophthalmic artery in two adult specimens. Segment $\mathrm{W}_{2}$ disappeared in (a), and segment $X$ disappeared in (b), resulting in the ophthalmic artery crossing over the optic nerve in both cases (reproduced from Hayreh $^{67}$ ). 

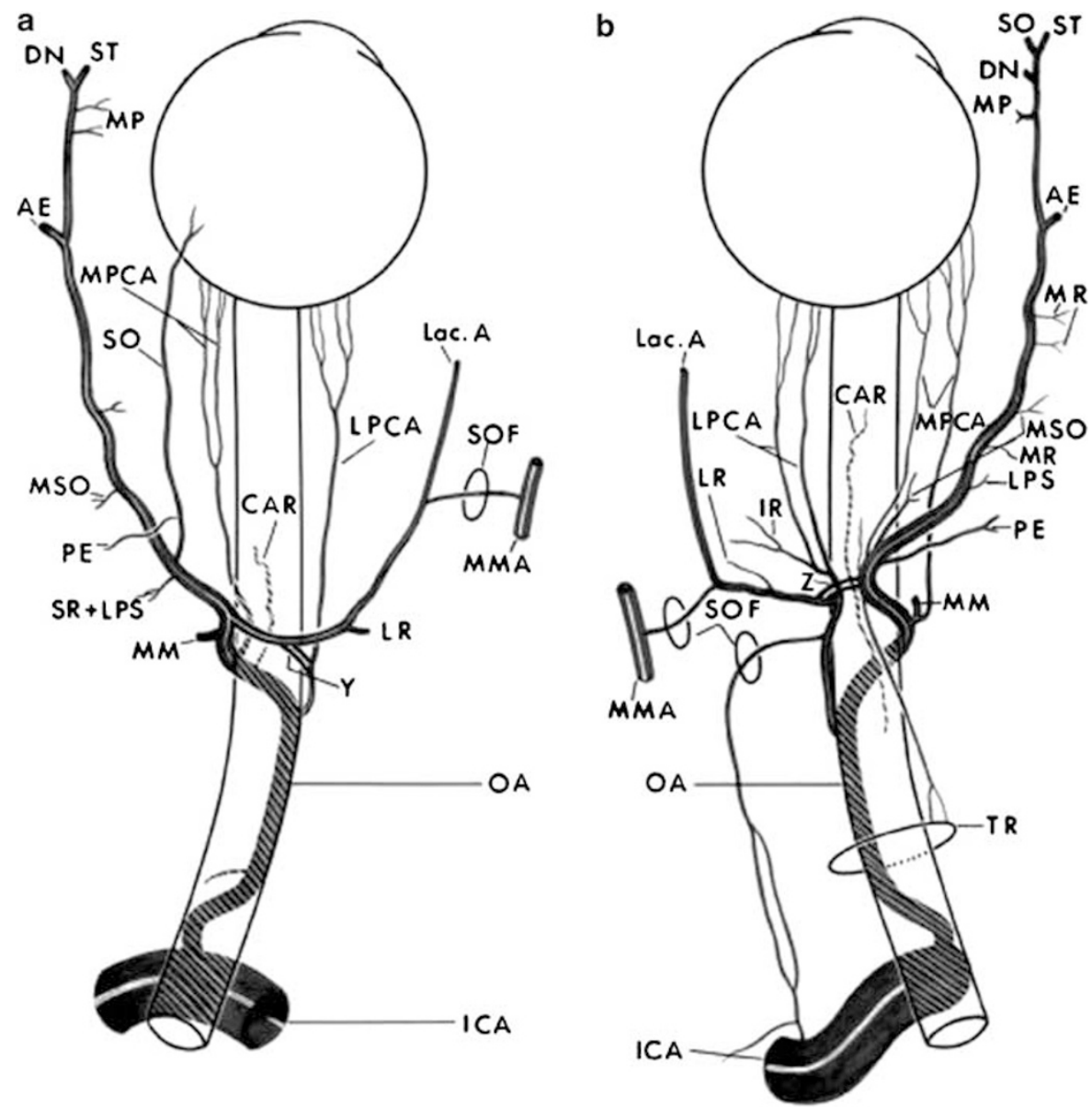

Figure 16 Origin, course, and branches of the ophthalmic artery in two adult specimens. Segment $Y$ disappeared in (a) and segment $\mathrm{Z}$ disappeared in (b), resulting in the ophthalmic artery crossing under the optic nerve in both. In (b) an anastomosis is seen in lateral wall of the cavernous sinus between the part of the internal carotid artery lying in proximal part of the cavernous sinus and a branch from the ophthalmic artery passing through the superior orbital fissure (reproduced from Hayreh ${ }^{67}$ ).

\section{Infraorbital artery}

This arises from the pterygopalatine part of the maxillary artery and lies in the infraorbital groove, where it gives off orbital branches. These branches supply the soft tissue of the orbital floor, lacrimal sac, nasolacrimal duct, and give a minor supply to the inferior rectus, inferior oblique, and orbicularis muscles. ${ }^{69}$

\section{Orbital branch of the middle meningeal artery}

This enters the orbit through the superior orbital fissure and anastomoses with the lacrimal artery. It does not usually contribute much to the blood supply of the orbit, but, as discussed above, in some cases this anastomosis can enlarge and either become major source of blood supply to the orbit or result in an abnormal origin of the ophthalmic artery from the middle meningeal artery. The developmental basis of that is discussed above.

\section{Orbital veins}

The orbital venous system is complex, highly variable, and confusing. In the orbit, in contrast to other parts of the body, there is no direct correspondence between the arteries and veins, except for the superior ophthalmic vein that has some correspondence with the ophthalmic artery. Also, the orbital veins, unlike the orbital arteries, have a highly variable and inconstant pattern and formation of venous networks at several places, resulting in marked uncertainty and controversy on their number, nomenclature and pattern. The latest detailed studies on the orbital venous system are those of Henry ${ }^{70}$ and Cheung and McNab. ${ }^{71}$

The orbital veins can be divided into two categories: 1 . main veins and 2 . inconstant veins. 


\section{Main orbital veins}

\section{Superior ophthalmic vein}

This is the largest orbital vein, and is the principal route of orbital venous drainage. Anteriorly at the superomedial corner of the orbital margin, it is usually formed by the union of two veins - the supraorbital and angular-just posterior to trochlea. ${ }^{71}$ It runs posteriorly along with the ophthalmic artery and leaves the orbit through the superior orbital fissure to join the cavernous sinus. Therefore, like the ophthalmic artery, its intraorbital course can be divided into three parts (see above). Main venous tributaries draining into it include the medial palpebral, superior vortex, anterior ethmoidal, lacrimal, central retinal, muscular, and the inferior ophthalmic veins. Brismar, ${ }^{72}$ on orbital phlebography, has described the anatomy and variations of the superior ophthalmic vein. The pattern of superior ophthalmic vein on orbital phlebography has been used for diagnosis of orbital mass lesions; however, Brismar ${ }^{72}$ cautions that since the pattern is not symmetrical between the two orbits, care must be taken in the diagnosis of space occupying orbital lesions from the venous asymmetries.

\section{Inferior ophthalmic vein}

This usually originates at the anterior, medial part of the orbital floor, from a venous network draining the lower lid, lacrimal sac region, inferior vortex veins, and inferior rectus and oblique muscles. In most cases, the vein runs posteriorly close to the orbital floor on the surface of the inferior rectus muscle, to join either the superior ophthalmic vein or the cavernous sinus directly. ${ }^{73}$

\section{Inconstant orbital veins}

Middle ophthalmic vein

This vein was first described by Henry. ${ }^{70}$ It drains the inferior network and runs posteriorly above the inferior rectus and between the superior and inferior ophthalmic veins. Some consider this as a second inferior ophthalmic vein because it is connected to the latter by collaterals. ${ }^{73}$ It joins the superior ophthalmic vein. Cheung and $\mathrm{McNab},{ }^{71}$ however, did not find this vein.

Medial ophthalmic vein Brismar ${ }^{72}$ described this in $40 \%$ of orbital phlebograms. According to him, it arises from the angular vein or the anterior part of the superior ophthalmic vein, and runs backward along the orbital roof and medial wall, and enters the cavernous sinus. However, Cheung and $\mathrm{McNab}^{71}$ reported this to have a very short course, running within the muscle cone and draining invariably into the superior ophthalmic vein.

\section{Collateral veins}

These essentially connect the superior venous system to the inferior venous system. ${ }^{71}$ Sesemann $^{74}$ in 1869 was one of the first to describe them; according to him, they connect the superior ophthalmic vein with the inferior ophthalmic vein. In his anatomical studies, Henry ${ }^{70}$ classified these into the following four types:

(i) Anterior collateral vein: This runs along the medial wall of the orbit, connecting the anterior medial network at the orbital floor and the angular vein.

(ii) Medial collateral vein: This is situated between the eyeball and medial rectus, connecting the anterior medial network at the orbital floor and the superior ophthalmic vein.

(iii) Lateral collateral vein: This lies on the lateral side of the muscular cone, connecting the inferior venous network and the lacrimal vein.

(iv) Posterior collateral vein: This is located in the posterior part of the orbit, connecting inferiorly located orbital veins and the superior ophthalmic vein.

On orbital phlebography, Brismar ${ }^{72}$ found an anterior collateral vein in $91 \%$, medial in $97 \%$, lateral in $72 \%$, and posterior in $19 \%$.

Chumg and $\mathrm{McNab}^{71}$ divided the orbital venous system essentially into superior and inferior orbital venous system, with superior and inferior ophthalmic veins, respectively, comprising the two venous systems, with several variations. They described the presence of only two collateral veins - medial and lateral, connecting the superior and inferior venous systems.

Apart from those, there are orbital venous networks. Among them, the most widespread one is the inferior venous network, which has been further subdivided into an anteroinferior network located in the muscle cone and a posteroinferior network. ${ }^{70}$ A superior network, located above the superior rectus and levator muscles, has also been described.

Apart from the above, there are named venous tributaries of the main veins and these include palpebral, vortex, lacrimal, muscular, ethmoidal, and central retinal veins. The central retinal vein, which drains blood from the retina and optic nerve, may join the superior or sometimes the inferior ophthalmic vein, or even the cavernous sinus directly. In my study, I found that the central retinal vein, after emerging from the optic nerve, may run for some distance in the substance of the dural sheath. The development of optic nerve sheath meningioma at or near the site of exit of the central retinal vein from the sheath results in a gradual occlusion of the central retinal vein, and that may cause the development of typical retinociliary collaterals on the 
optic disc - a well-known sign of optic nerve sheath meningioma.

The intraorbital veins have multiple communications with the surrounding extraorbital veins, for example, anteriorly with the facial and frontal veins, posteriorly with the cavernous sinus, inferiorly with the pterygoid plexus, and medially with the nasal veins via the ethmoid veins.

\section{Abbreviation}

Key to abbreviations used in illustrations throughout this article

A, bony intracranial part of optic canal; AE, anterior ethmoid artery; Ant. Clin. Process, anterior clinoid process; Ant. Sup. Hyp. Art., anterior superior hypophyseal artery; Br., branch; B.S., body of sphenoid bone; CAR, central artery of retina; Col.Br., collateral branch; CZ, circle of Zinn and Haller; D, dura mater; DN, dorsal nasal artery; D.S./DS, dural sheath of the optic nerve; Dup. OC, duplicate optic canal; I.C.A./ICA, internal carotid artery; IO, muscular artery to inferior oblique; IR, muscular artery to inferior rectus; Lac. A./ Lac., lacrimal artery; LPCA, lateral posterior ciliary artery; LPS, muscular artery to levator palpebrae superioris ; LR, muscular artery to lateral rectus; MM/ Med.Mus., medial muscular artery; MMA, middle meningeal artery; MP, medial palpebral artery; MPCA, medial posterior ciliary artery; MR, muscular artery to medial rectus; MSO, muscular artery to superior oblique; O.A./OA, ophthalmic artery; OC, optic canal; O.N./ON, optic nerve; Orb. Per., orbital periosteum; $\mathrm{P}$, periosteum; PE, posterior ethmoid artery; P.P.S./PPS, point of penetration of dural sheath; Rec.Br.CZ, recurrent branches of Circle of Zinn and Haller; SAS, subarachnoid space; SO, supraorbital artery; $\mathrm{SOF}$, superior orbital fissure; SR, muscular artery to superior rectus; ST, supratrochlear artery; Stap. A., stapedial artery; Supra-Orb. Br., supraorbital branch; $\mathrm{TR}$, tendinous ring; 1. 11. 1ll, first, second, and third parts of ophthalmic artery.

\section{Acknowledgements}

I am grateful to Ms Georgiane Perret for help with bibliography, to Ms Trish Duffel with illustrations, and to my wife Shelagh for her help in the preparation of this manuscript.This was supported in part by unrestricted grant from Research to Prevent Blindness Inc., New York and Dr SS Hayreh is a Research to Prevent Blindness Senior Scientific Investigator

\section{References}

1 Meyer F. Zur Anatomie der Orbitalarteien. Morphol Jahr 1887; 12: 414-458.

2 Hayreh SS, Dass R. The ophthalmic artery. I. Origin and intra-cranial and intra-canalicular course. $\mathrm{Br} J$ Ophthalmol 1962; 46: 65-98.

3 Hayreh SS, Dass R. The ophthalmic artery. II. Intraorbital course. Br J Ophthalmol 1962; 46: 165-185.

4 Hayreh SS. The ophthalmic artery. III. Branches. $\mathrm{Br}$ J Ophthalmol 1962; 46: 212-247.

5 Krause W. Anatomische Varietaten, Tabellen, etc. Hahn'sche Buchhandlung: Hanover 1880, p 156.

6 Tode JC. Medizinisch-chirurgische Bibliothek. Copenhagen. 1787; 10: 408

7 Otto A. De animalium quorundam, per hiemem dormientium, vasis cephalicis et aure interna epistola. Acta Phys Med Acad. Caes, Leopold. Carol T 1826; 13: 23-86.

8 Quain J. The Anatomy of the Arteries of the Human Body. Taylor \& Walton: London, 1844.

9 Peugnet E. Osteo-aneurysm of inferior maxilla. Med Rec 1876; 11: 81-84.

10 Wyeth JA. Essays in Surgical Anatomy and Surgery. William Wood: NewYork, 1879.

11 Wernitz A. Die Spina Bifida in aetiologischer und klinischer Beziehung. Inaugural dissertation, Dorpat, 1880.

12 Flemming EE. Absence of the left internal carotid. J Anat Physiol 1895; 29: 13-14.

13 Fisher AGT. A case of complete absence of both internal carotid arteries, with a preliminary note on the developmental history of the stapedial artery. J Anat Physiol 1914; 48: 37-46.

14 Lowrey LG. Anomaly in the circle of Willis, due to absence of the right internal carotid artery. Anat Rec 1916; 10: 221-222.

15 Fife CD. Absence of the common carotid. Anat Rec 1921; 22: 114-121.

16 Poppi U. Mancanza unilaterale della carotide interna. Monit Zool Ital 1928; 39: 42-52.

17 Hindze B, Freidmann L. Die topographische Verbreitung der peripherischen Hirnarterien eines Menschen bei rudimentärer Entwicklung einer der inneren Carotiden. $Z$ Gesamte Neurol Psych 1931; 132: 458-474.

18 Töndury G. Einseitiges Fehlen der A. carotis interna. Morphol Jahr 1934; 74: 624-638.

19 Boyd JD. Absence of the right common carotid artery. J Anat 1934; 68: 551-557.

20 Hyrtl J. Beiträge zur pathologischen Anatomie des Gehörorganes. Med Jahr Oest Staates 1836; 10: 457-469;11: 421-423.

21 Hyrtl J. Handbuch der Anatomie des Menschen. W Braumueller, Vienna, 1879.

22 Guinard A. Traitement des anévrysmes de la base du cou par la ligature simultanée de la carotide primitive et de la sous-clavière droite. Ann Malad Orielle Larynx 1896; 22 393-408.

23 Orr AE. A rare anomaly of the carotid arteries (internal and external). J Anat Physiol 1906; 41: 51.

24 Tiedemann F. Tabulae arteriarum corporis humani. Fig 4. W Würmel: Mannheim, 1824.

25 Blandin PF. Traité d'anatomie topographique. Germer-Baillière: Paris, 1834.

26 Dubrueil JM. Des anomalies artérielles. Germer-Baillière: Paris, 1847 
27 Luschka H. Die Anatomie des Menschen, Vol 3, Part 2. Der Kopf. H Laupp: Tübingen, 1867.

28 Cruveilhier J. Traité d'anatomie descriptive, 4 ed. Vol 3. Labbé: Paris, 1871.

29 Curnow J. Two instances of irregular ophthalmic and middle meningeal arteries. J Anat Physiol 1874; 8: 155-156.

30 Henle J. Anatomie des Menschen. Braunschweig: Vieweg, 1876.

31 Schafer EA, Thane GD, editors. Quain's elements of anatomy. 10th ed. Vol, 2, part 2. Longmans, Green \& Co.: London, New York, 1892.

32 Musgrove J. Origin of the ophthalmic artery from the middle meningeal. J Anat Physiol 1893; 27: 279-281.

33 Jazuta KS. Zur Anatomie der Art. men. med. des Menschen und der Säugetiere. Dissertation, Petersburg 1905. (cited by Keller).

34 Adachi B. Das Arteriensystem der Japaner. Vol 1: KaiserlichJapanischen Universität: Kyoto, 1928.

35 Whitnall SE. The Anatomy of the Human Orbit. 2nd ed. Oxford University Press: London, 1932.

36 Chanmugam PK. Note on an unusual ophthalmic artery associated with other abnormalities. J Anat 1936; 70: 580-582.

37 Harvey JC, Howard LM. Rare type of anomalous ophthalmic artery in a Negro. Anat Rec 1945; 92: 87-90.

38 Hollinshead WH. Anatomy for Surgeons. Vol 1, Paul B Hoeber Inc: New York, 1954.

39 Priman J, Christie DH. A case of abnormal internal carotid artery and associated vascular anomalies. Anat Rec 1959; 134: 87-95.

40 Gillilan LA. Significant superficial anastomoses in the arterial blood supply to the human brain. J Comp Neurol 1959; 112: 55-74.

41 Gillilan LA. The collateral circulation of the human orbit. Arch Ophthalmol 1961; 65: 684-694.

42 Keller HL. Varianten der Arteria carotis interna, der Arteria meningea media und der Arteria ophthalmica im Karotisangiogramm. Fortschr Geb Roentgenstr Nuklearmed 1961; 95: 472-482.

43 Liu Q, Rhoton AL. Middle meningeal origin of the ophthalmic artery. Neurosurgery 2001; 49: 401-406.

44 von Haller A. Iconum anatomicarum corporis humani. Fasc 7. Vandenhoeck: Göttingen, 1781.

45 Murray A. A Description of the Arteries of the Human body, (Translated by A Scott). Bell, Bradfute \& Balfour: Edinburgh, 1801.

46 Velpeau ALM. Traité complet d'anatomie chirurgicale, générale et topographique du corps humain. Méquignon-Maarvis Père \& Fils: Paris, 1833.

47 Arnold F. Handbuch der Anatomie des Menschen mit besonderer Rücksicht auf Physiologie und praktische Medicin. Vol 2, part 2: Herder'sche Verlagshandlung: Fribourg, 1847.

48 Barkow JCL. Comparative Morphologie des Menschen und der menschenähnlichen Thiere. In: Die Blut-Gefässe vorzüglich die Schlagadern der Säugethiere in ihren wesentlichsten Verschiedenheiten. F Hirt: Breslau, Vol 4, Table 18, Figure 3. 1866.

49 Merkel F. Makroscopische Anatomie. In: Graefe-Saemisch Handbuch der gesammten Augenheilkunde. Vol 1. W Engelmann: Leipzig, 1910.

50 Duke-Elder S. Text-Book of Ophthalmology. Vol 1. CV Mosby: St Louis, 1932.

51 Schaeffer JP. Morris's Human Anatomy, 11 ed. Blakiston: New York, 1953.
52 Johnston TB, Davies DV, Davies J. Gray's anatomy, 32 ed. Longmans, Green \& Co. Ltd: London, 1958.

53 Zuckerkandl E. Zur Anatomie der Orbitalarterien. Med Jahr 1876; 6: 343.

54 Stattin S. Meningeal vessels of the internal carotid artery and their angiographic significance. Acta Radiol 1961; 55: 329-336.

55 Vogelsang H. Über eine angiographische selten nachzuweisende Anastomose zwischen dem A. carotis interna und dem A. carotis externa-Kreislauf. Nervenarzt 1961; 32: 518-520.

56 Dilenge D, David M, Fischgold H. Artère ophtalmique et tumeurs frontales intracraniennes. Neurochirurgie 1962; 8: 379-384.

57 Bernasconi V. Abnormal origin of the middle meningeal artery from the ophthalmic artery. Neurochirurgia 1965; 8: 81-85.

58 Pretterklieber ML, Krammer EB. Sphenoidal artery, ramus orbitalis persistens and pterygospinosus muscle - a unique cooccurrence of first branchial arch anomalies in man. Acta Anat 1996; 155(2): 136-144.

59 Parsons JH. The Ocular Circulation. Bale, Sons \& Danielsson: London, 1903.

60 Duke-Elder S. System of ophthalmology, Vol. 1 CV Mosby Co: St Louis, 1958.

61 Hayreh SS. The orbital vessels of rhesus monkeys. Exp Eye Res 1964; 3: 16-30.

62 Dilenge D, Fischgold H, David M. L'Angiographie par soustraction de l'artère ophtalmique et de ses branches. Masson \& Cie: Paris, 1965.

63 Levy JV, Zemek L. Ophthalmic arteriovenous malformation. Am J Ophthalmol 1966; 62: 971-974.

64 Lombardi G. Ophthalmic artery anomalies. Ophthalmologica 1969; 157: 321-327.

65 Honma Y, Ogawa T, Nagao S. Angiographically occult anomalous ophthalmic artery arising from the anterior cerebral artery. Acta Neurochir 1997; 139: 480-481.

66 Sade B, Tampieri D, Mohr G. Ophthalmic artery originating from basilar artery: a rare variant. Am J Neurorad 2004; 25: 1730-1731.

67 Hayreh SS. Arteries of the orbit in the human being. Br J Surg 1963; 50: 938-953.

68 Padget DH. The development of the cranial arteries in the human embryo. Contribution to Embryology, No. 212, Carnegie Institution of Washington Publication 575 1948; 32: 205-261.

69 Salamon G, Raybund C, Grisoli F. Anatomical study of the blood vessels of the orbit. Proceedings Second Congress of European Ass Radiol. Amsterdam. Excerpta Medica: Amsterdam, 1971, pp 284-289.

70 Henry JGM Contribution à l'étude de l'anatomie des vaisseux de l'orbite et de la loge caveneuse - par injection de matières plastiques - du tendon de Zinn et de la capsule de Tenon. Thèse de Paris 1959.

71 Cheung N, McNab AA. Venous anatomy of the orbit. Invest Ophthalmol Vis Sci 2003; 44: 988-995.

72 Brismar J. Orbital phlebography. II. Anatomy of superior ophthalmic vein and its tributaries. Acta Radiol Diagn 1974; 15: 481-496.

73 Brismar J. Orbital phlebography. III. Topography of intraorbital veins. Acta Radiol Diagn 1974; 15: 577-594.

74 Sesemann E. Die orbitalvenen des Menschen und ihr zusammenhang mit den oberflächlichen venen des kopfes. Arch Anat Physiol Wiss Med 1869; 2: 154-173. 